\title{
ANALISIS KEBIJAKAN DIVIDEN DI INDONESIA TAHUN 2013-2017
}

\author{
Ninnasi Muttaqiin \\ Program Studi S1 Manajemen, Fakultas Ekonomi dan Bisnis \\ Universitas Nahdlatul Ulama Surabaya \\ e-mail: m.ninnasi@unusa.ac.id
}

\begin{abstract}
The purpose of this study is to analyze factors that influence dividend policy in Indonesia. The independent variables in this study are return on equity (ROE), current ratio (CR), debt to equity ratio (DER), company size, company growth, and free cash flow (FCF), while the dependent variable is dividend policy proxied by dividend payout ratio (DPR) variable. This study uses secondary data from the financial statements of non-financial companies listed on the IDX during 2013 to 2017. The sample technique used is purposive sampling which resulted in a sample of 12 companies. The analytical tool for testing hypothesis is SPSS version 21. This study shows that ROE has a positive and not significant effect on dividend policy. CR, DER, and FCF have a significant positive effect on dividend policy. The size of the company and the company's growth have a negative and not significant effect on dividend policy.
\end{abstract}

Keywords: dividend policy, dividend payout ratio, return on equity, current ratio, debt to equity ratio, company size, and company growth

\section{PENDAHULUAN}

Ketika memutuskan untuk berinvestasi, investor dapat menanamkan asetnya pada dua jenis pasar keuangan, yakni pasar uang dan pasar modal. Produk yang diperjualbelikan di pasar modal berupa surat berharga yang kontraknya bersifat jangka panjang (long-term) atau lebih dari satu tahun. Jenis produknya adalah saham, baik saham biasa maupun saham istimewa, surat utang atau obligasi, reksadana, dan produk derivatif. Produk yang paling digemari adalah saham atau surat berharga berupa bukti kepemilikan atas suatu perusahaan. Ketika investor memutuskan untuk menanamkan modalnya dalam bentuk pembelian saham, investor akan terlebih dahulu melihat bagaimana kinerja perusahaan di pasar modal. Salah satu faktor yang menjadi penilaian adalah bagaimana pola perusahaan dalam pembagian dividen. Kieso et al. (2010) menjelaskan bahwa dividen merupakan pembagian laba perusahaan kepada pemegang saham. Dividen yang dibagikan berasal dari laba bersih perusahaan setelah dikurangi bunga dan pajak.

Dalam penentuan pembagian dividen, perusahaan dihadapkan pada dua pilihan yaitu membagikan dividen atau menahan dana yang digunakan untuk pembagian dividen dan mengalokasikannya untuk pendanaan investasi. Pihak manajemen perusahaan akan mengalami dilemma ketika menentukan keputusan pembagian laba karena jika perusahaan membagikan dividen, hal itu bisa menjadi signal bagi investor bahwa perusahaan memiliki kinerja keuangan yang baik, stabil, bahkan meningkat. Sebaliknya, jika perusahaan tidak membagikan dividen maka dianggap sebagai penurunan kinerja keuangan perusahaan.

Pentingnya asumsi mengenai kebijakan pembagian dividen ini menyebabkan pihak manajemen harus lebih memahami faktor apa saja yang memengaruhi kebijakan dividen perusahaan. 
Berdasarkan data dari situs resmi PT Bursa Efek Indonesia, rata-rata dividend payout ratio perusahaan non-keuangan di Indonesia mengalami fluktuasi atau tidak stabil pada periode 2013 hingga 2017. Pada tahun 2015, rata-rata dividen mencapai nilai tertinggi yaitu $65 \%$ dibandingkan dengan dua tahun sebelum dan sesudahnya yang mana tahun 2013 senilai 59\%, tahun 2014 senilai 46\%, tahun 2016 60\%, dan 49\% pada tahun 2017. Hal ini menjadi perhatian bagi investor yang mengharapkan stabilitas pembagian dividen.

Indikator untuk mengukur besarnya dividen yang dibagikan pada pemegang saham adalah dividend payout ratio. Rasio pembayaran dividen merupakan rasio antara besarnya dividen yang dibayarkan pada pemegang saham dibandingkan dengan total pendapatan bersih perusahaan pada periode tertentu. Terdapat berbagai faktor yang memengaruhi kebijakan dividen, antara lain faktor keuntungan perusahaan atau profitabilitas, besarnya utang perusahaan, likuiditas perusahaan, dan ukuran perusahaan.

Penelitian Eltya et al. (2016) dan Indrawan et al. (2017) menyatakan bahwa ROE berpengaruh positif signifikan terhadap DPR, sedangkan Rafique (2012) menyatakan bahwa ROE berpengaruh negatif tidak signifikan terhadap DPR. Nurhayati (2013) dan Eltya et al. (2016) menyatakan CR berpengaruh negatif signifikan terhadap DPR, sedangkan Indrawan et al. (2017) menyatakan bahwa CR berpengaruh positif signifikan terhadap DPR. Rafique (2012) dan Indrawan et al. (2017) menyatakan bahwa DER berpengaruh positif terhadap DPR, sedangkan Komrattanapanya (2013), Deni et al. (2016), Eltya et al. (2016), dan Fitri et al. (2016) menyatakan bahwa DER berpengaruh negatif terhadap DPR. Rafique (2012), Komrattanapanya (2013), dan Deni et al. (2016) menyatakan bahwa ukuran perusahaan berpengaruh positif signifikan terhadap DPR, sedangkan Nurhayati (2013) dan Eltya et al. (2016) menyatakan ukuran perusahaan berpengaruh negatif terhadap DPR. sedangkan Indrawan et al. (2017) menyatakan bahwa pertumbuhan perusahaan berpengaruh positif terhadap DPR, sedangkan Rafique (2012) dan Komrattanapanya (2013) menyatakan bahwa pertumbuhan perusahaan berpengaruh negatif terhadap DPR. Lucyanda dan Lilyana (2012) dan Prasetio dan Bambang (2016) menyatakan bahwa FCF berpengaruh positif signifikan terhadap DPR.

\section{TUJUAN PENELITIAN}

Tujuan dari penelitian ini adalah untuk mengetahui pengaruh ROE, CR, DER, ukuran perusahaan, pertumbuhan perusahaan, dan FCF secara parsial terhadap kebijakan dividen pada perusahaan di Indonesia tahun 2013 hingga 2017.

\section{HIPOTESIS PENELITIAN}

\section{Hubungan antara Variabel Independen terhadap Variabel Dependen}

Signaling Theory menyebutkan bahwa pembagian dividen dianggap sebagai sinyal bagi investor bahwa perusahaan mampu dengan baik mengelola keuangan perusahaan sehingga bisa memberikan keuntungan atau profit yang kemudian dibagikan kepada para pemegang saham dalam bentuk dividen. Eltya et al. (2016) dan Indrawan et al. (2017) menyatakan bahwa ROE berpengaruh positif signifikan terhadap DPR maka dapat diambil hipotesis sebagai berikut.

$\mathrm{H}_{1}=$ ROE berpengaruh signifikan terhadap kebijakan dividen

Likuiditas perusahaan adalah tolak ukur untuk menilai kemampuan perusahaan dalam memenuhi kewajiban jangka pendeknya. Rasio untuk 
mengukur likuiditas perusahaan adalah menggunakan rumus current ratio. Nurhayati (2013) dan Eltya et al. (2016) menyatakan CR berpengaruh negatif signifikan terhadap DPR, sedangkan Indrawan et al. (2017) menyatakan bahwa CR berpengaruh positif signifikan terhadap DPR maka dapat diambil hipotesis sebagai berikut.

$\mathrm{H}_{2}=\mathrm{CR}$ berpengaruh signifikan terhadap kebijakan dividen

Rasio Leverage adalah rasio yang digunakan untuk mengetahui tingkat penggunaan utang jangka panjang perusahaan dalam mendanai aktivitas perusahaan. Semakin tinggi penggunaan utang atau dana eksternal, maka akan semakin tinggi pula kewajiban perusahaan dalam melunasi pinjaman yang kemudian mampu memengaruhi besarnya tingkat pembagian dividen. Untuk mengukur rasio leverage dapat menggunakan DER. Rafique (2012) dan Indrawan et al. (2017) menyatakan bahwa DER berpengaruh positif terhadap DPR, sedangkan Komrattanapanya (2013), Deni et al. (2016), Eltya et al. (2016), dan Fitri et al. (2016) menyatakan bahwa DER berpengaruh negatif terhadap DPR. Maka dapat diambil hipotesis sebagai berikut.

$\mathrm{H}_{3}=$ DER berpengaruh signifikan terhadap kebijakan dividen

Perusahaan dengan ukuran yang besar dalam memiliki kemudahan memasuki pasar modal sehingga lebih mudah pula memperoleh kepercayaan investor. Semakin besar perusahaan, semakin besar pula jumlah asset yang dikelola dan semakin tinggi pula kemungkinan perusahaan memperoleh keuntungan. Keuntungan tersebut dapat digunakan sebagai dana pembagian dividen. Rafique (2012), Komrattanapanya (2013), dan Deni et al. (2016) menyatakan bahwa ukuran perusahaan berpengaruh positif signifikan terhadap DPR ma$\mathrm{ka}$ dapat diambil hipotesis sebagai berikut.

$\mathrm{H}_{4}=$ Ukuran Perusahaan berpengaruh signifikan terhadap kebijakan dividen
Perusahaan dengan pertumbuhan yang tinggi memiliki kecenderungan untuk terus menggunakan dana dalam jumlah besar guna mendanai operasional usahanya. Guna memenuhi kebutuhan tersebut, perusahaan akan memilih menahan dananya untuk digunakan sebagai modal investasi demi pertumbuhan usahanya, karena itu semakin kecil pula dana yang tersisa untuk dibagikan kepada pemegang saham dalam bentuk dividen. Rafique (2012) menyatakan bahwa pertumbuhan perusahaan tidak berpengaruh signifikan terhadap DPR. Maka dapat diambil hipotesis sebagai berikut.

$\mathrm{H}_{5}=$ Pertumbuhan Perusahaan berpengaruh tidak signifikan terhadap kebijakan dividen

Free cash flow atau arus kas bebas merupakan besarnya dana yang tersedia untuk digunakan demi peningkatan nilai perusahaan di masa mendatang. Perusahaan dapat menggunakan arus kas bebas untuk mendanai investasi, membagikannya sebagai dividen, atau menjadikannya tambahan modal berupa laba ditahan. Lucyanda dan Lilyana (2012) dan Prasetio dan Bambang (2016) menyatakan bahwa FCF berpengaruh positif signifikan terhadap DPR. Maka dapat diambil hipotesis sebagai berikut.

$\mathrm{H}_{6}=$ FCF berpengaruh signifikan terhadap kebijakan dividen

\section{METODE PENELITIAN}

\section{Jenis dan Sumber Data}

Penelitian ini menggunakan pendekatan kuantitatif dengan data sekunder yang berasal dari laporan keuangan perusahaan, laporan tahunan perusahaan, dan fact book yang diambil dari situs resmi Bursa Efek Indonesia (BEI) selama tahun 2013 hingga 2017. 


\section{Populasi dan Sampel}

Populasi dalam penelitian ini adalah 468 perusahaan non-keuangan yang telah go-public dan terdaftar di Bursa Efek Indonesia untuk periode 2013, 2014, 2015, 2016, dan 2017.

Sampel penelitian ini adalah 12 perusahaan yang memenuhi kriteria pengambilan sampel. Kriteria sampel dalam penelitian ini yaitu perusahaan non-keuangan yang telah go-public dan terdaftar di Bursa Efek Indonesia mulai tahun 2013 hingga 2017, melaporkan laporan keuangan dan laporan tahunan secara rutin, menggunakan mata uang rupiah, dan rutin membayarkan dividen selama periode tahun 2013 hingga 2017.

\section{Analisis Data}

Metode yang digunakan dalam penelitian ini adalah analisis regresi logistik untuk menganalisis data kuantitatif dengan bantuan program pengolah data statistik SPSS versi 21 .

\section{HASIL DAN PEMBAHASAN}

\section{Analisis Statistik Deskriptif}

Statistik deskriptif bertujuan menggambarkan berbagai karakteristik data yang berasal dari sampel penelitian. Data yang digunakan adalah mean dan standard deviation. Deskripsi

Tabel 1 Statistik Deskriptif

\begin{tabular}{|l|c|c|c|}
\hline & N & Mean & Std. Deviation \\
\hline DPR & 43 & 58.61 & 32.13 \\
\hline ROE & 43 & 17.99 & 14.65 \\
\hline CR & 43 & 218.8 & 67.82 \\
\hline DER & 43 & 26.85 & 1.87 \\
\hline Ukuran & 43 & 0.657 & 0.4234 \\
\hline Pertumbuhan & 43 & 8.675 & 9.7452 \\
\hline FCF & 43 & 37.56 & 52.82 \\
\hline Valid N (listwise) & 43 & & \\
\hline
\end{tabular}

Sumber: data yang diolah, 2019 dari setiap variabel penelitian ini dapat dilihat pada Tabel 1.

\section{Uji Asumsi Klasik}

\section{Uji Multikolinearitas}

Uji multikolinearitas menggunakan nilai tolerance $>0,1$ dan nilai varian inflation factor $(\mathrm{VIF})<10$. Hasil uji multikolinearitas penelitian ini adalah sebagai berikut.

Tabel 2 Hasil Uji Multikolinearitas

\begin{tabular}{|l|c|c|}
\hline \multirow{2}{*}{\multicolumn{1}{|c|}{ Model }} & \multicolumn{2}{c|}{ Collinearity Statistics } \\
\cline { 2 - 3 } & Tolerance & VIF \\
\hline (Constant) & & \\
\hline ROE & 0.765 & 1.422 \\
\hline CR & 0.238 & 3.986 \\
\hline DER & 0.221 & 4.589 \\
\hline Ukuran & 0.287 & 3.292 \\
\hline Pertumbuhan & 0.894 & 1.201 \\
\hline FCF & 0.344 & 2.659 \\
\hline
\end{tabular}

Sumber: data yang diolah, 2019

Tabel 2 menunjukkan bahwa nilai tolerance adalah lebih dari 0,1 dan nilai VIF lebih dari 10, maka dapat disimpulkan bahwa variabel independen bebas dari multikolinearitas.

\section{Uji Heteroskedastisitas}

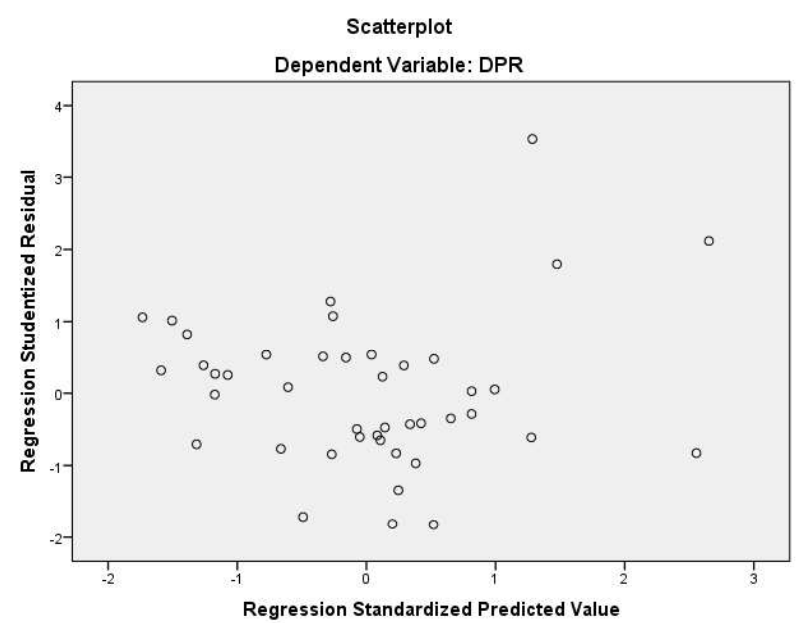

Gambar 1 Hasil Uji Heteroskedastisitas 
Berdasarkan hasil pengujian pada Gambar 1, terlihat pola Scatter Plot dari regresi menyebar. Hal tersebut menunjukkan bahwa tidak ada gejala heteroskedastisitas.

\section{Uji Autokorelasi}

Tabel 3 Hasil Uji Autokorelasi

\begin{tabular}{|l|r|}
\hline & \multicolumn{2}{|c|}{$\begin{array}{c}\text { Unstandardized } \\
\text { Residual }\end{array}$} \\
\hline Test Value & 0.70318 \\
\hline Cases < Test Value & 21 \\
\hline Cases > = Test Value & 22 \\
\hline Total Cases & 43 \\
\hline Number of Runs & 28 \\
\hline Z & 1.564 \\
\hline Asymp. Sig. (2-tailed) & 0.124 \\
\hline
\end{tabular}

Sumber: data yang diolah, 2019

Nilai Asymp.Sig (2-tailed) sebesar 0,124 yang artinya lebih besar dari 0,05, maka dapat disimpulkan bahwa tidak terdapat gejala autokorelasi.

\section{Analisis Regresi Berganda}

Tabel 4 Hasil Analisis Regresi Berganda

\begin{tabular}{|l|r|r|c|}
\hline \multirow{2}{*}{ Model } & \multicolumn{2}{|c|}{$\begin{array}{c}\text { Unstandardized } \\
\text { Coefficients }\end{array}$} & $\begin{array}{c}\text { Standardized } \\
\text { Coefficients }\end{array}$ \\
\cline { 2 - 4 } & \multicolumn{1}{|c|}{ B } & \multicolumn{1}{c|}{ Std. Error } & Beta \\
\hline (Constant) & 284.21 & 104.282 & \\
\hline ROE & 0.246 & 0.258 & 0.211 \\
\hline CR & 0.323 & 0.110 & 0.688 \\
\hline DER & 74.488 & 24.798 & 0.763 \\
\hline Ukuran & -12.020 & 3.811 & -0.653 \\
\hline Pertumbuhan & -0.465 & 0.337 & -0.129 \\
\hline FCF & 3.664 & 0.442 & 0.389 \\
\hline
\end{tabular}

Sumber: data yang diolah, 2019.

Persamaan regresi dari Tabel 4 adalah sebagai berikut.

$$
\begin{aligned}
\mathrm{Y}= & 284,21+0,246 \mathrm{ROE}+0,323 \mathrm{CR}+ \\
& 74,488 \mathrm{DER}-12,020 \text { Ukuran }-0,465 \\
& \text { Pertumbuhan }+3,664 \mathrm{FCF}+e
\end{aligned}
$$

\section{Uji Hipotesis}

Uji Statistik t

Tabel 5 Hasil Uji Statistik t

\begin{tabular}{|l|c|c|}
\hline \multicolumn{1}{|c|}{ Model } & $\mathbf{t}$ & Sig. \\
\hline (Constant) & 2.704 & 0.008 \\
\hline ROE & 0.890 & 0.299 \\
\hline CR & 3.021 & 0.003 \\
\hline DER & 3.106 & 0.002 \\
\hline Ukuran & -3.237 & 0.122 \\
\hline Pertumbuhan & -1.246 & 0.200 \\
\hline FCF & 2.324 & 0.026 \\
\hline
\end{tabular}

Sumber: data yang diolah, 2019

Uji statistik $\mathrm{t}$ bertujuan mengetahui pengaruh parsial dari variabel ROE, CR, DER, Ukuran Perusahaan, Pertumbuhan Perusahaan, dan FCF secara signifikan atau tidak signifikan terhadap variabel DPR. Nilai signifikansi yang digunakan adalah 0,05 .

\section{Pengaruh ROE terhadap kebijakan dividen}

Variabel ROE memiliki nilai signifikansi sebesar 0, 299 yaitu lebih besar dari 0,05. Hasil tersebut menunjukkan bahwa hipotesis $\left(\mathrm{H}_{1}\right)$ yang berbunyi "ROE berpengaruh signifikan terhadap kebijakan dividen" ditolak.

Hasil penelitian ini menunjukkan bahwa ROE berpengaruh tidak signifikan terhadap kebijakan dividen. Hal ini disebabkan karena besar kecilnya profitabilitas perusahaan kurang berpengaruh pada kebijakan dividen karena bagaimanapun kondisi profit perusahaan, perusahaan akan selalu memiliki kewajiban untuk membagikan dividen sebagai bentuk tanggung jawab kepada para pemegang saham perusahaan. 


\section{Pengaruh CR terhadap kebijakan dividen}

Variabel CR memiliki nilai signifikansi sebesar 0, 003 yaitu lebih kecil dari 0,05. Hasil tersebut menunjukkan bahwa hipotesis $\left(\mathrm{H}_{2}\right)$ yang berbunyi "CR berpengaruh signifikan terhadap kebijakan dividen" diterima.

Hasil penelitian menunjukkan bahwa CR berpengaruh signifikan terhadap kebijakan dividen. Pengaruh tersebut dikarenakan semakin tinggi nilai CR perusahaan maka semakin baik pula perusahaan dalam memenuhi kewajiban jangka pendeknya. Ketika perusahaan memiliki kemampuan yang baik dalam memenuhi kewajiban jangka pendek, maka perusahaan akan memiliki lebih banyak laba bersih yang kemudian bisa dijadikan sebagai dana untuk pembagian dividen perusahaan.

\section{Pengaruh DER terhadap kebijakan dividen}

Variabel DER memiliki nilai signifikansi sebesar 0,002 yaitu lebih kecil dari 0,005. Hasil tersebut menunjukkan bahwa hipotesis $\left(\mathrm{H}_{3}\right)$ yang berbunyi "DER berpengaruh signifikan terhadap kebijakan dividen" diterima.

Hasil penelitian menunjukkan bahwa DER berpengaruh signifikan terhadap kebijakan dividen. Nilai DER yang semakin rendah menyebabkan perusahaan dianggap lebih suka menggunakan dana internal untuk membiayai kebutuhan usahanya dibandingkan dengan penggunaan dana eksternal. Semakin rendah nilai DER juga mampu memberikan peluang tingginya tingkat pembayaran dividen pada pemegang saham.

\section{Pengaruh ukuran perusahaan terhadap kebijakan dividen}

Variabel ukuran perusahaan memiliki nilai signifikansi sebesar 0,122 yaitu lebih besar dari
0,005. Hasil tersebut menunjukkan bahwa hipotesis $\left(\mathrm{H}_{4}\right)$ yang berbunyi "Ukuran perusahaan berpengaruh signifikan terhadap kebijakan dividen" ditolak.

Hasil penelitian menunjukkan bahwa ukuran perusahaan berpengaruh tidak signifikan terhadap kebijakan dividen. Besar kecilnya perusahaan tidak memengaruhi kebijakan dividen karena berapa pun skala dan ukuran perusahaan, ketika perusahaan memutuskan untuk menggunakan pendanaan eksternal berupa saham, maka perusahaan juga harus berkewajiban membagikan keuntungan pada para pemegang saham melalui pembagian dividen.

\section{Pengaruh pertumbuhan perusahaan terhadap kebijakan dividen}

Variabel pertumbuhan perusahaan memiliki nilai signifikansi sebesar 0,200 yaitu lebih besar dari 0,005. Hasil tersebut menunjukkan bahwa hipotesis $\left(\mathrm{H}_{5}\right)$ yang berbunyi "Pertumbuhan perusahaan berpengaruh tidak signifikan terhadap kebijakan dividen" diterima.

Hasil penelitian menunjukkan bahwa pertumbuhan perusahaan berpengaruh tidak signifikan terhadap kebijakan dividen. Perusahaan yang ingin mengembangkan usahanya, akan berencana untuk menggunakan labanya sebagai dana investasi guna meningkatkan pertumbuhan perusahaan. Hal tersebut menyebabkan kecilnya kemungkinan pembagian dividen kepada pemegang saham.

\section{Pengaruh FCF terhadap kebijakan dividen}

Variabel FCF memiliki nilai signifikansi 0,026 yaitu lebih kecil dari 0,005. Hasil tersebut menunjukkan bahwa hipotesis $\left(\mathrm{H}_{6}\right)$ yang berbunyi "FCF berpengaruh signifikan terhadap kebijakan dividen" diterima. 
Hasil penelitian menunjukkan bahwa FCF berpengaruh signifikan terhadap kebijakan dividen. Tingginya nilai FCF atau arus kas bebas menunjukkan bahwa perusahaan memiliki jumlah laba yang besar pula sebagai sumber dana untuk pembagian dividen kepada pemegang saham.

\section{KESIMPULAN}

Berdasarkan hasil analisis data dan pembahasan, dapat ditarik kesimpulan sebagai berikut.

1. ROE berpengaruh positif tidak signifikan terhadap kebijakan dividen perusahaan di Indonesia tahun 2013 hingga 2017.

2. CR, DER, dan FCF berpengaruh positif signifikan terhadap kebijakan dividen perusahaan di Indonesia tahun 2013 sampai 2017.

3. Ukuran perusahaan dan pertumbuhan perusahaan berpengaruh negatif tidak signifikan terhadap kebijakan dividen perusahaan di Indonesia tahun 2013 sampai 2017.

\section{SARAN}

Berdasarkan hasil dan keterbatasan penelitian, maka dapat diberikan saran sebagai berikut.

1. Bagi perusahaan agar lebih memperhatikan posisi utang dan ketersediaan arus kas bebas perusahaan, karena hal tersebut merupakan faktor yang berpengaruh dalam penentuan kebijakan dividen perusahaan.

2. Bagi peneliti selanjutnya agar menyertakan variabel independen lebih banyak lagi, seperti rasio profitabilitas menggunakan ROA, GPM, dan NPM, rasio likuiditas menggunakan quick ratio, rasio leverage menggunakan DAR, dan menambahkan beberapa variabel lain di luar perusahaan.
3. Bagi investor agar lebih memperhatikan data laporan keuangan perusahaan dalam kurun waktu yang lebih dari lima tahun untuk mendapatkan pandangan yang lebih luas mengenai kemampuan perusahaan dalam membagikan dividennya sebelum memutuskan untuk berinvestasi.

\section{DAFTAR RUJUKAN}

Brigham, Eugene F dan Houston Joel F. 2010. Dasar-Dasar Manajemen Keuangan. Buku 1. Edisi Kesebelas. Jakarta: Salemba Empat.

. 2014. Dasar-Dasar Manajemen Keuangan, Buku 2, Edisi Kesebelas. Jakarta: Salemba Empat.

Deni, Febrianto Frans, Aisjah Siti, dan Dzajuli Atim, 2016. Analisis Variabel-Variabel yang Mempengaruhi Kebijakan Dividen (Studi pada Perusahaan Manufaktur yang Terdaftar di Bursa Efek Indonesia). Jurnal Aplikasi Manajemen (JAM), Vol. 14, No. 2.

Eltya, Sandy, Topowijono, dan Azizah Devi Farah. 2016. Pengaruh Leverage, Likuiditas, Profitabilitas, dan Ukuran Perusahaan Terhadap Kebijakan Dividen (Studi pada Perusahaan Perbankan yang Terdaftar di Bursa Efek Indonesia Periode 2012-2014). Jurnal Administrasi Bisnis (JAB) Universitas Brawijaya Malang, Vol. 38, No. 2.

Fitri, Rembulan Rahmadia, Hosen Muhamad Nadratuzzaman, dan Muhari Syafaat. 2016. Analysis of Factors that Impact Dividend Payout Ratio on Listed Companies at Jakarta Islamic Index. International Journal of Academic Research in Accounting, Finance, and Management Sciences, ISSN 2308-0337 Vol. 6, No. 2, pp 87-97. 
Hanafi, M. dan Halim, A. 2016. Analisis Laporan Keuangan, Edisi Kelima. Yogyakarta: UPP. STIM YKPN.

Kasmir. 2011. Analisis Laporan Keuangan. Cetakan Ketiga. Jakarta: PT Raja Grafindo Persada.

Kieso, Donald E., Weygant Jerry J., dan Warfield Terry D. 2010. Intermediate Accounting. $13^{\text {th }}$. New Jersey: John Wiley and Sons Inc.

Komrattanapanya, Pornumpai. 2013. Factors Influencing Dividend Payout in Tahiland: A Tobit Regression Analysis. International Journal of Accounting and Financial Reporting, ISSN 2162-3082 Vol. 3 No. 2.

Lucyanda, Jurica dan Lilyana. 2012. Pengaruh Free Cash Flow dan Struktur Kepemilikan Terhadap Dividend Payout Ratio. Jurnal Dinamika Akuntansi, ISSN 2085-4277, Vol. 4, No. 2, pp 129-138.

Munawir, S. 2010. Analisis Laporan Keuangan Edisi Keempat. Yogyakarta: Liberty. . 2012. Analisis Laporan Keuangan, Edisi Keempat Cetakan Keenam. Yogyakarta: Liberty.

Nazir, Mohammad. 2005. Metode Penelitian. Bogor: Ghalia Indonesia.

Nurhayati, Mafizatun. 2013. Profitabilitas, Likuiditas, dan Ukuran Perusahaan Pengaruhnya Terhadap Kebijakan Dividen dan Nilai Perusahaan Sektor Non Jasa. Jurnal Keuangan dan Bisnis Universitas Mercu Buana Jakarta, Vol. 5, No. 2.

Prasetio, Djoko Adi dan Bambang Suryono. 2016. Pengaruh Profitabilitas, Free Cash Flow, Investment Opportunity Set Terhadap Dividend Payout Ratio. Jurnal Ilmu dan Riset Akuntansi Sekolah Tinggi Ilmu Ekonomi Indonesia (STIESIA) Surabaya, Vol. 5, No. 1.

Rafique, Mahira. 2012. Factors Affecting Dividend Payout: Evidence from Listed NonFinancial Firms of Karachi Stock Exchange. Journal Faculty of Management Sciences International Islamic University Islamabad Pakistan, Vol. 1, No. 11, pp 76-92.

Ross, S.A., Westerfield R.W., dan Jordan B.D. 2006. Corporate Finance Fundamental, Edisi Ketujuh. McGrawHill.

Sartono, Agus. 2009. Manajemen Keuangan Perusahaan Teori dan Praktik. Jakarta: Erlangga.

Sesilia, Ella dan Oetomo Haning Widi. 2015. Pengaruh Rasio Keuangan dan Economic Value Added Terhadap Harga Saham. Jurnal Ilmu dan Riset Manajemen Sekolah Tinggi Ilmu Ekonomi Indonesia (STIESIA) Surabaya, Vol. 4, No. 8.

Sudana, I Made. 2015. Manajemen Keuangan Perusahaan Teori dan Praktik, Edisi Kedua. Jakarta: Penerbit Erlangga.

Sugiyono. 2008. Metode Penelitian Bisnis. Bandung: Alfabeta.

. 2012. Metode Penelitian Bisnis. Bandung: Alfabeta.

Sujarweni, V. Wiratna. 2015. Metode Penelitian Bisnis dan Ekonomi, Cetakan Pertama. Yogyakarta: Pustaka Baru Press.

www.bps.go.id diakses pada 18 Mei 2019. www.idx.co.id diakses pada 20 Mei 2019. www.ojk.go.id diakses pada 21 Mei 2019. www.sahamok.com diakses pada 21 Mei 2019. 